AUSTRALIAN JOURNAL OF BASIC AND
ASPL: $1991-8178$
EISSN: $2309-8414$
DOI: $10.22587 /$ ajbas.2017.11.13.7
Journal home page: www.ajbasweb.com

\title{
Thymoquinone Pre-and Post-Treatment Effects on Ehrlich Ascites Carcinoma Induced Albino Mice: An in vivo study.
}

\author{
${ }^{1}$ Amira O. Abd El-Azim, ${ }^{2}$ Sayed K. Areida and ${ }^{3}$ Maggie E. Amer \\ ${ }^{1}$ Zoology Department, Faculty of Science, Mansoura University, Mansoura, Egypt (assistant professor) PhD. \\ ${ }^{2}$ Zoology Department, Faculty of Science, Mansoura University, Mansoura, Egypt (associate professor) PhD. \\ ${ }^{3}$ Zoology Department, Faculty of Science, Mansoura University, Mansoura, Egypt (teaching assistant) MSc.
}

\section{Address For Correspondence:}

Amira Othman Abd El-azim, Ph.D Department of Zoology, Faculty of Science, Mansoura University, Mansoura, Egypt.

E-mail:amirahosman2000@yahoo.com; Mob.:+201000489538; Postal code: 35516

\section{ARTICLE INFO}

\section{Article history:}

Received 19 August 2017

Accepted 1 November 2017

Available online 11 November 2017

Keywords:

Ehrlich ascites carcinoma, liver,

Thymoquinone, Ki-67, PCNA.

\begin{abstract}
A B S T R A C T
Background: Chemoprevention is an effective approach towards cancer regulation. For that, it is important nowadays to investigate more active and influential natural products, which have a powerful capability to fight cancer cells. Thymoquinone was the selected natural product for the current study to investigate its probable anticancer property in Ehrlich ascites carcinoma (EAC) inoculated mice within both cases of preand post-treatment. Objective: The present research was assumed to evaluate both the protective and therapeutic anti-cancer influence of Thymoquinone (TQ) against Ehrlich ascites carcinoma (EAC) inoculated mice. Experimental mice were split into five sets: 1) control group, 2) TQ group: mice were orally injected with $(10 \mathrm{mg} / \mathrm{kg})$ for four weeks. 3)EAC group: mice were intramuscularly inoculated with EAC $\left(2.5 \times 10^{6}\right)$ cells once, 4) TQ+EAC group: mice were previously orally injected with TQ two weeks before experiment, then were intramuscularly inoculated with EAC, 5) EAC+TQ group: mice were injected with EAC and TQ at the same time till last day of experiment. All animals' liver and tumors were collected and examined histologically (H\&E), histochemical (Feulgen stain reaction), ultra structurally (transmission electron microscope) and immunohistochemically (PCNA antigen \& Ki-67 antigen). Results: All results demonstrated that treatment with TQ showed alike features like normal and TQ groups through varying degrees. In addition, there was a great superiority of TQ pre-treated group than post-treated one. Conclusion: this study evidently illustrated that Thymoquinone could perfectly prevent and/or protect cancer incidence, effectively retarding tumor progress and so, it is significantly recommended to be considered as a part of our daily diet. Overall, extra evaluation of Thymoquinone is strongly recommended in clinical fields to outline its possible value to be utilized as an innovative complementary remedy for cancer diseases.
\end{abstract}

\section{INTRODUCTION}

Cancer is considered a common reason of death all over the world (Global Burden of Disease Cancer and others, 2015). EAC is one of the major suggested tumor modeling in experimental research. It is defined as an undifferentiated carcinoma with great transplantable ability, quick proliferation, tinier life period, one hundred percent malignancy. EAC does not possess tumor-specific transplantation antigen (TSTA) (Ozaslan and others, 2011). Routine medications have been unsuccessful or even non-influential for intact cells, so, from this point, exploiting of natural agents as an alternative cancer therapy is believed to be valuable for cancer management and destruction. Chemoprevention is considered to be a promising approach for cancer inhibition today, that is identified as utilizing of natural agents (individually or combination) to restrain cancer progression. Recently, the use of freshly synthesized small particles, the combination of naturally occurring substances or therapeutic modalities to inhibit cancer recurrence and/or progress has become broadly established(Apryshko and others, 2005; Stojkovic and Radacic, 2002; Xie and others, 2006). Thymoquinone comprises the principal component

Open Access Journal

Published BY AENSI Publication

(C) 2017 AENSI Publisher All rights reserved

This work is licensed under the Creative Commons Attribution International License (CC BY).

http://creativecommons.org/licenses/by/4.0/

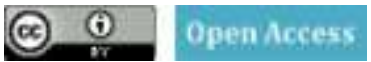

To Cite This Article: Amira O. Abd El-Azim, Sayed K. Areida and Maggie E. Amer., Thymoquinone Pre-And Post-Treatment Effects on Ehrlich Ascites Carcinoma Induced Albino Mice: An in vivo study. Aust. J. Basic \& Appl. Sci., 11(13): 64-79, 2017 
of Nigella sativa seeds. It exhibited anti-neoplastic, anti-neoplastic, and anti-inflammatory actions in both in vivo and in vitro(Asaduzzaman Khan and others, 2017; Gali-Muhtasib and others, 2006).

\section{MATERIALS AND METHODS}

\subsection{Animals:}

Fifty male Swiss albino mice, 6-8 weeks age, weighing 19 $\pm 2 \mathrm{~g}$, were purchased from Theodore Bilharz Research Institute, Egypt. Animals and their care were in conformity with the National Institutes of Health $(\mathrm{NIH})$ policies for laboratory animals nursing and use. Mice were accommodated in metabolic cages under wellorganized environmental circumstances $\left(25^{\circ} \mathrm{C}\right.$ and a $12 \mathrm{~h}$ light/dark cycle $)$. Animals were always supplied with tap water and standard diet.

\subsection{Materials:}

Thymoquinone was purchased from Sigma - Aldrich Company Ltd. (The old Brickyard, New Road, Gillinham, United Kingdom). EAC was kindly provided by The Pharmacology and Experimental Oncology Unit of the National Cancer Institute, Cairo University, Egypt, and was preserved through continuous inoculation of $\left(2.5 \times 10^{6}\right)$ cells intraperitoneally.(Badr El-Din et al., 2007)(Badary and others, 2007). The ascetic fluid was gathered via an insulin syringe from the intraperitoneal cavity.

\subsection{Experimental design:}

Fifty mice were separated into10 mice for each cage. Group (1): was considered as the typical control. Group (2): based on LD50 (TQ) was administered to mice orally via gavage after being dissolved in bi-distilled water at a dose of $10 \mathrm{mg} / \mathrm{kg} /$ day for 4 sequential weeks (Al-Ali and others, 2008; Badary and others, 1998; Nagi and others, 1999). Group3: (EAC) $0.2 \mathrm{~mL}$ Ehrlich Ascites Carcinoma (EAC) $\left(2.5 \times 10^{6}\right.$ cells) were intramuscularly injected at the lower limb's right thigh only once at the beginning of the experiment. Group (4): (TQ+EAC) animals were pre-treated with TQ $(10 \mathrm{mg} / \mathrm{kg} / \mathrm{day})$ orally for 2 weeks before intramuscularly inoculated with $0.2 \mathrm{~mL}$ (EAC) $\left(2.5 \times 10^{6}\right.$ cells) similarly then left to the end of the experiment. Group (5): (EAC+TQ) mice were intramuscularly injected alike with $0.2 \mathrm{~mL}$ (EAC) $\left(2.5 \times 10^{6}\right.$ cells) then they received TQ $(10 \mathrm{mg} / \mathrm{kg} / \mathrm{day})$ orally after 8 days for a whole month. All mice were sacrificed and samples were collected after 4 weeks.

\subsection{Histopathological investigation:}

All liver and tumor samples were collected, washed three times cautiously via saline solution, then fixed in $10 \%$ prepared formalin solution, processed and converted to paraffin blocks. A thickness of 4- $\mu$ m sections were cut. Haematoxylin and eosin stained slides were used for the histological examination.

\subsection{Electron Microscopy:}

The common technique for transmission electron microscope for specimen preparation was applied (Kasas and others, 2003) consequently, samples examination were performed through an electron microscope (TEM, 100CX, JEOL, USA) (Kasas and others, 2003).

\subsection{Histochemical Investigations (Feulgen reaction for DNA):}

Further sections were stained by Periodic acid-Schiff stain for DNA detection (Garvin and others, 1976).

\subsection{Immunohistochemical investigation:}

Slides with tissues were deparaffinized, hydrated in descending sequences of alcohol, and kept in antigen retrieval (slides were boiled at $98^{\circ} \mathrm{C}$ in $10 \mathrm{mmol} / \mathrm{L}$ sodium citrate buffer for 20 minutes). To block endogenous peroxidase sections were treated with $3 \% \mathrm{H}_{2} \mathrm{O}_{2}$. Monoclonal antibody mouse MAb anti-rat Ki-67 and mouse $\mathrm{MAb}$ anti-PCNA were used. Consequently, sections were processed classically according to (Horiguchi and others, 2007). Assessment of Ki-67 and PCNA labeling index was dependent upon the staining intensity and the proportion of +ve cells, where 5-8 areas per specimen were randomly chosen. Results were represented by the mean number of counted +ve cells per particular area. 


\subsection{Statistical analysis:}

Data were represented as the mean \pm SE. Statistics were estimated with SPSS program. Significant variances between groups were calculated by means of One-way ANOVA test and when P-value $<0.05$, this reflected significant variation.

\section{Results:}

\subsection{Body weight changes:}

Figures (i) represented the effect of TQ administration on body weight (g), tumor weight (g) in Ehrlich Solid Carcinoma bearing mice.

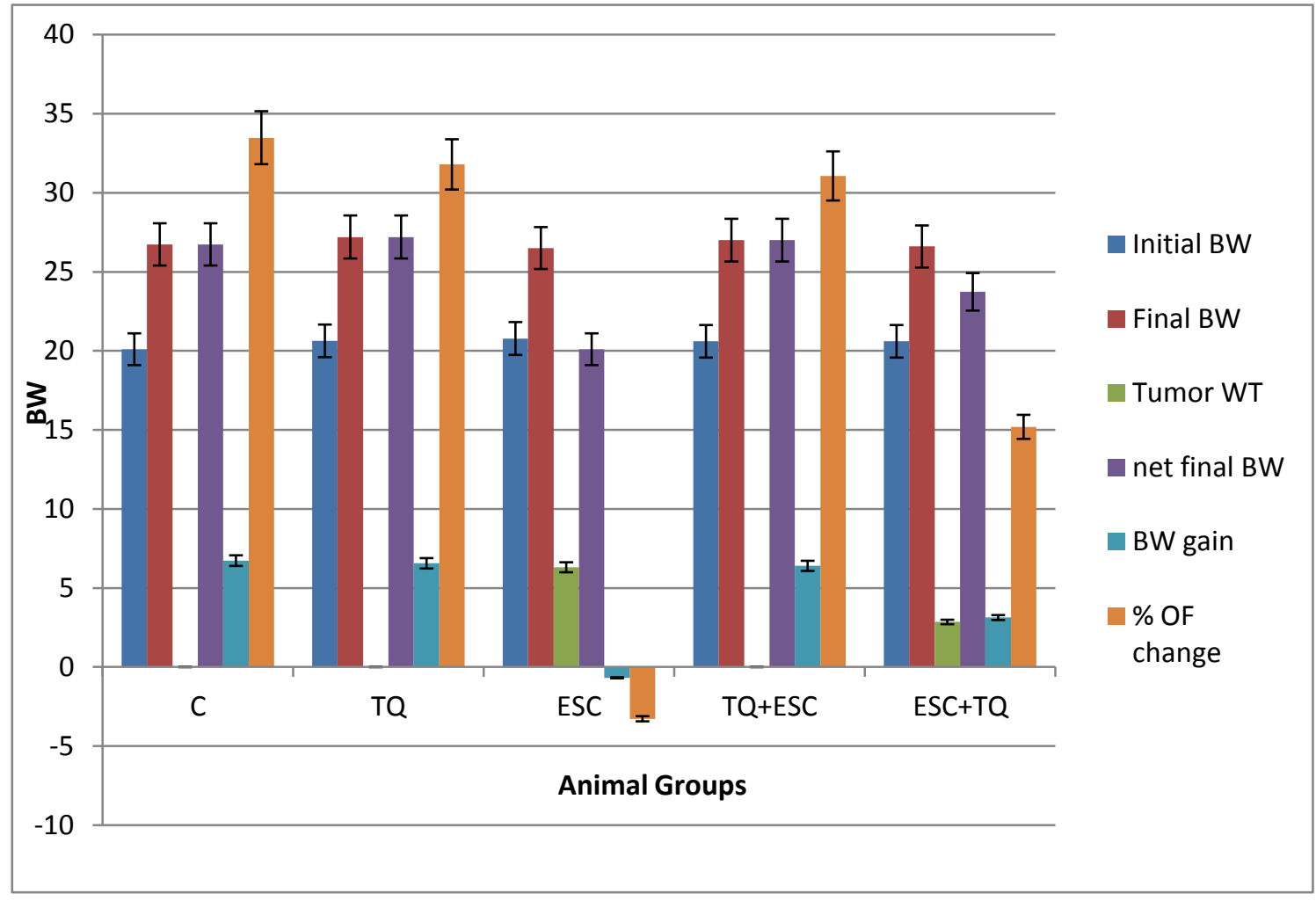

Fig.(i): Body weight $(\mathrm{g})$ and tumor weight $(\mathrm{g})$ in control and different treated group.

\subsection{Body weight $(B W)$ :}

Figure (i) showed the effect of TQ administration in initial, final and net final BWs changes in Ehrlich solid carcinoma (ESC) bearing mice.

As shown in figure (i), TQ injected animals displayed insignificant variation from control in body weight gain. Whereas EAC inoculated group showed significant decrease in body weight gain compared to normal one. This decrease was overcome in (TQ+EAC) injected mice when compared to ESC group. (EAC+TQ) group revealed also a considerable rise in body weight compared to EAC inoculated one but with lower degree than those of (TQ+EAC) group.

\subsection{Histological investigations:}

Light microscopic examination of the liver of control animals treated with saline solution only showed healthy hepatic construction which was composed of hepatic lobules with radiating cords that are made up of hepatocytes extending from the portal region to central vein. Sinusoids located between cords and lined with endothelial cells. Space of Disse was localized between the sinusoid and the hepatocyte. Von Kupffer cells were projected into the sinusoid lumen Figure 1a.

Examination of liver sections from Thymoquinone treated animals displayed classical hepatic structure resembling those of control animals Figure $1 \mathrm{~b}$. 
Ehrlich tumor cells inoculated into animals induced intramuscular tumors at the injected spot. These masses were protruding and showed quick progression associated with various inflammatory reaction and lymphocytic response demonstrating a constant proliferation action Figure 1g.

In the specimen examined after one month of subcutaneous inoculation with a single dose of Ehrlich tumor cells led to severe pathological alterations including perivascular round cell infiltration. Hydropic degeneration (Oedema) was also seen in severely injured hepatocytes, large numbers of liver cells had undergone degeneration, such as; focal necrosis, congestion in the central vein, and infiltration of lymphocytes was obviously seen Figures 1c, $1 \mathrm{~d}$.

Abnormalities of the hepatocyte nuclei like multinucleated giant cells, pyknosis, and karyorrhexis were also noted. Activated Kupffer cells and hepatic cirrhosis were obviously seen among expanded sinusoidal spaces. EAC inoculated animals pre-treated with TQ group failed to develop solid tumors. Remarkable restoration of normal cell structure was noticed. The hepatocytes were regular, with normal size, normal homogenous cytoplasm with a rounded nucleus. Cells nuclei size was alike that of control one, also cells containing two nuclei were significantly less than in EAC group. An absence of cirrhosis, bile duct proliferation, and carcinoma was noticed. The hepatotoxicity produced by ESC cells were almost eliminated by the protective effect of TQ extract administration Figure 1e. In ESC inoculated animals post-treated with TQ, solid tumor size were reduced about $69.47 \%$. However, there was no effect on skin and revealed by normal hair follicles and skin. Increased necrosis as well as a noticeable reduction in mitosis occurrence indicating slow development. There was an evident drop in tumor size and appeared growing slow and broken into parts after treatment with TQ. Fewer sinusoids dilation and reduction of leucocytic infiltration were also significant. However, Kupffer cells still active. In addition, few foci spots of inflammatory and/or necrotic cells can be seen. Chromatinolysis, pyknosis, and apoptosis were the major nuclear modifications detected within mice. This point to a limited prevention of ESC cells by TQ extract Figure 1f.
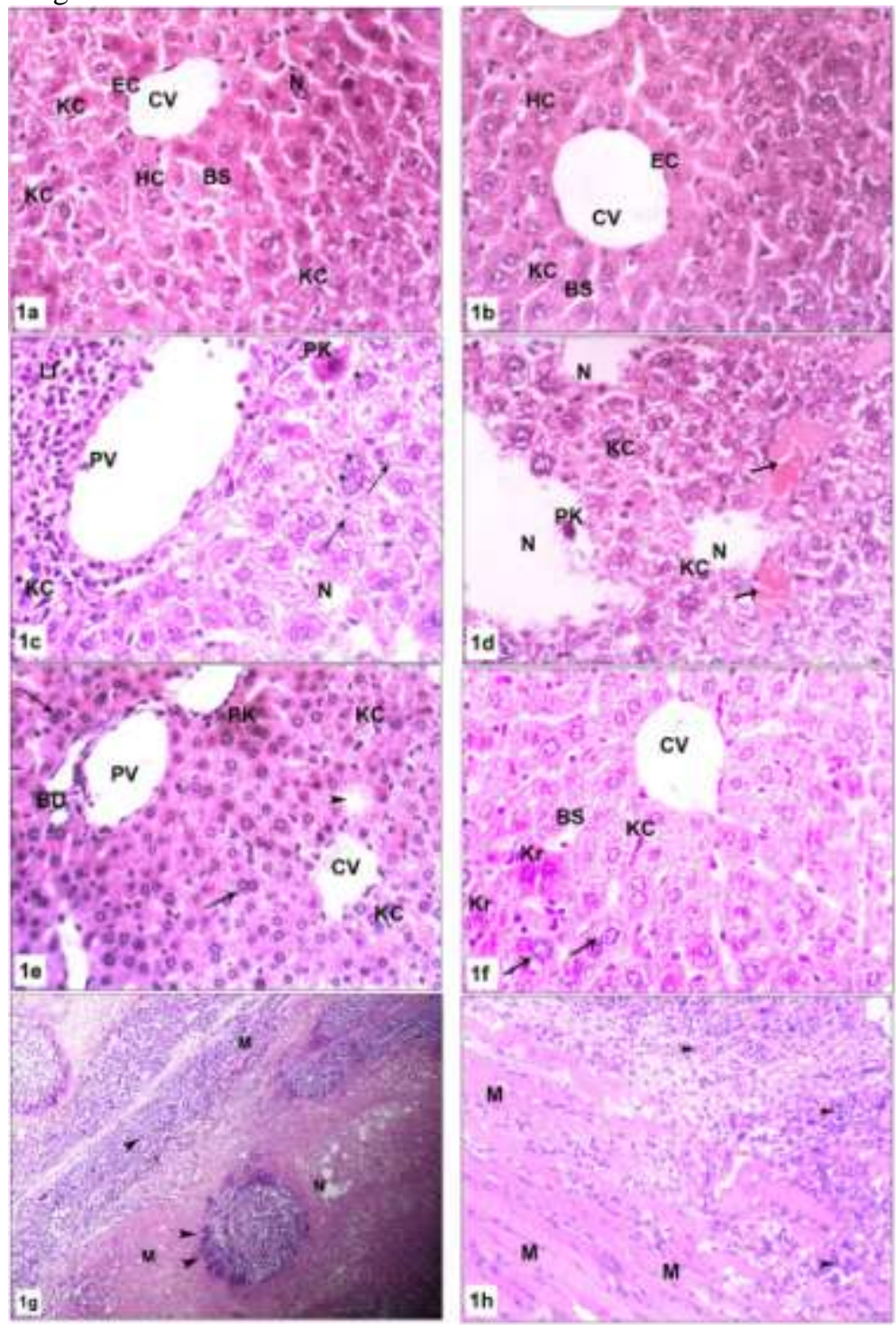
Fig. 1: Photomicrograph of liver and tumor sections in mice stained with Hx\&E (a,b) control and TQ treated groups respectively illustrating normal hepatocyte $(\mathrm{HC})$, blood sinusoid (BS), central vein (CV), normal endothelial cells (EC) and Kupffer cells (KC),(c,d) Ehrlich inoculated group showed great injured hepatic showing focal necrosis (N), Pyknotic nucleus (PK), leucocytic infiltration (LI), portal vein (PV), activated Kupffer cells (KC), karyorrhexis (*), and feathery degeneration (arrows)hemorrhage (arrows) respectively, (e) TQ pre-treated EAC inoculated group with dilated portal vein (PV) with bile duct (BD), Kupffer cell (KC), pyknotic nuclei (PK), binucleated hepatocyte (arrows), and necrosis (arrow heads), (f) Post-treated EAC inoculated group demonstrated, giant cell (arrow), dilated blood sinusoid (BS), activated Kupffer cell (KC) and karyorrhexis (Kr), (g,h) A longitudinal section of Ehrlich tumor bearing mouse thigh muscle group and TQ post- treated EAC inoculated group tumor respectively showing focal necrosis $(\mathrm{N})$, and muscle fibers (M), invaded by sheets of tumor cells (arrow heads), and the last photo displayed almost normal muscle fibers $(\mathrm{M})$ pressing on tumor cells (arrow heads). (X 400).

\subsection{Histochemical investigations:}

The use of Feulgen histochemical technique was for the assessment of apoptosis. Control group showed a higher content of coarse chromatin that appeared magenta red in color inside the nuclei of cells indicates the presence of DNA with evident mitotic figures in some cells. The cytoplasm showed a negative Feulgen reaction indicating the absence of any detectable DNA inclusion Figure 2a.

In TQ treated mice showed similar results as that of control group Figure $2 b$.

Hepatocytes of Ehrlich inoculated mice showed a marked decrease in the DNA content seemed faintly stained suggesting that the DNA has probably degraded Figure 2c,2d.

The EAC group previously treated with TQ liver sections had a moderate reaction than did the control group, but more than the EAC inoculated rats post-treated with TQ Figure 2e. The EAC treated with TQ previously showed a rise in colored DNA constituent parts. The inflammatory cells included nuclei were densely stained Figure $2 \mathrm{f}$. 

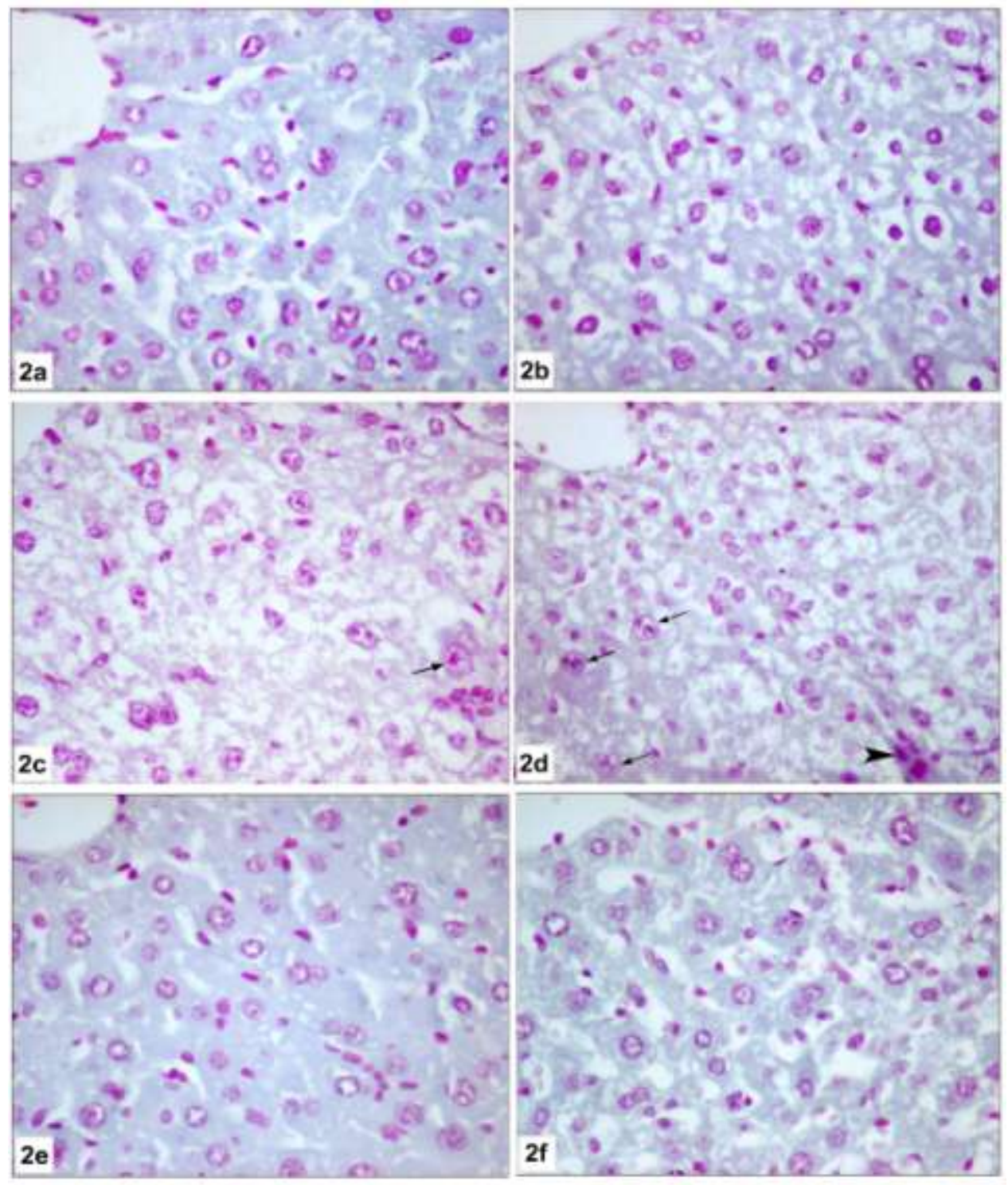

Fig. 2: Photomicrograph of liver mice stained with Feulgen reaction $(a, b)$ control and TQ treated group showed normal content of DNA in the hepatocytes indicated by intense magenta colour. (c,d)EAC inoculated group displaying weak Feulgen reaction indicating the depletion of DNA containing nuclei of hepatocytes, giant cell (arrow), pyknosis (arrowhead), (e) TQ pre-treated EAC inoculated animals illustrating strong Feulgen reaction indicating the increment of DNA containing hepatocyte nuclei (f) TQ post-treated EAC inoculated animals displaying moderate DNA content within hepatocytes' nuclei as indicated by the moderate magenta red colour. (X 400).

\subsection{Electron microscopic investigations:}

In electron microscopic preparations, liver of control animals revealed normal hepatocytes with large nucleus that contains large amount euchromatin spread between heterochromatin that was dispersednear the margins of the nuclear cover and within the nuclei. A distinct spherical and centrally located nucleolus was also present. Numerous rounded and elongated mitochondrial profiles with well-developed transversal cristae were located. Well-designed rough endoplasmic reticulum carried ribosomes was noticed in the cytoplasm. Microvilli projected into the bile canaliculi lumen. Space of Disse was facing the blood sinusoids and contained microvilli. There were several types of healthy junctions. Endothelial and Kupffer cells were lined the sinusoidal walls Figure 3a.

Electron microscopic examination liver samples of Thymoquinone treated mice demonstrated similar features as those of the control group Figure $3 \mathrm{~b}$.

In contrast to the previous results, ultrastructural observations carried out on liver tissues of EAC inoculated animals revealed several morphological alterations like irregular envelope and there were nuclei were with evident chromatolysis. In other instances, pyknotic and apoptotic nuclei with irregular nuclear membrane were 
observed. The presence of "microvilli" appeared clearly all over most the nuclei of this group. There were rough endoplasmic reticulum wrapping atrophied mitochondria.

Fat droplets occurred isolated in the cytoplasm. There were also excessive amount of red blood cells referring to congested blood vessels. Cell junctions were rarely found, and the space of Disse lost its microvilli. Also, constricted bile canaliculi lacking their microvilli were detected Figures $3 \mathrm{c}, 3 \mathrm{~d}$. Certain tumor cells possessed elevated quantities of glycogen; others were having curved nuclei surrounding the lipid to some extent Figure $3 g$.

Uultrastructural micrographs for liver of animals pre-protected with TQ against Ehrlich inoculated animals showed remarkable improvement. The nuclei were almost alike those of normal mice. Mitochondria, rough and smooth endoplasmic reticulum in most instances were as normal as those of control outlines. Bile canaliculi raised in size and were completely established. On the other hand, blood sinusoids have the characteristic appearance of those of control counterpart as well as Kupffer cells Figure 3e.

Examination of animals post-treated with Thymoquinone displayed partial amelioration with few pathological alterations compared to the previous group. However, there were some shrinkage in some nuclei accompanied by irregular nuclear membrane. Kupffer cells were still large and activated. In few spots, the space of Disse was not fully formed. There were also some degenerated mitochondria with few or incompletely cristae and less abundant and dilated rough endoplasmic reticulum. In some foci, some junctions between cells were noticed clearly and karyorrhexis was obviously seen Figure 3f. All these features confirmed that the tumor still present and was not totally damaged. There was major variation in the shape of isolated tumors of this group. Certain apoptotic bodies that revealed membrane blebbing went through a process of cytoplasmic breakup. In addition, some foci displayed pyknotic or karyolitic nuclei. Cytoplasm contained malformed mitochondria, plentiful vacuoles and tiny profiles of endoplasmic reticulum were evident Figure $3 \mathrm{~h}$. 


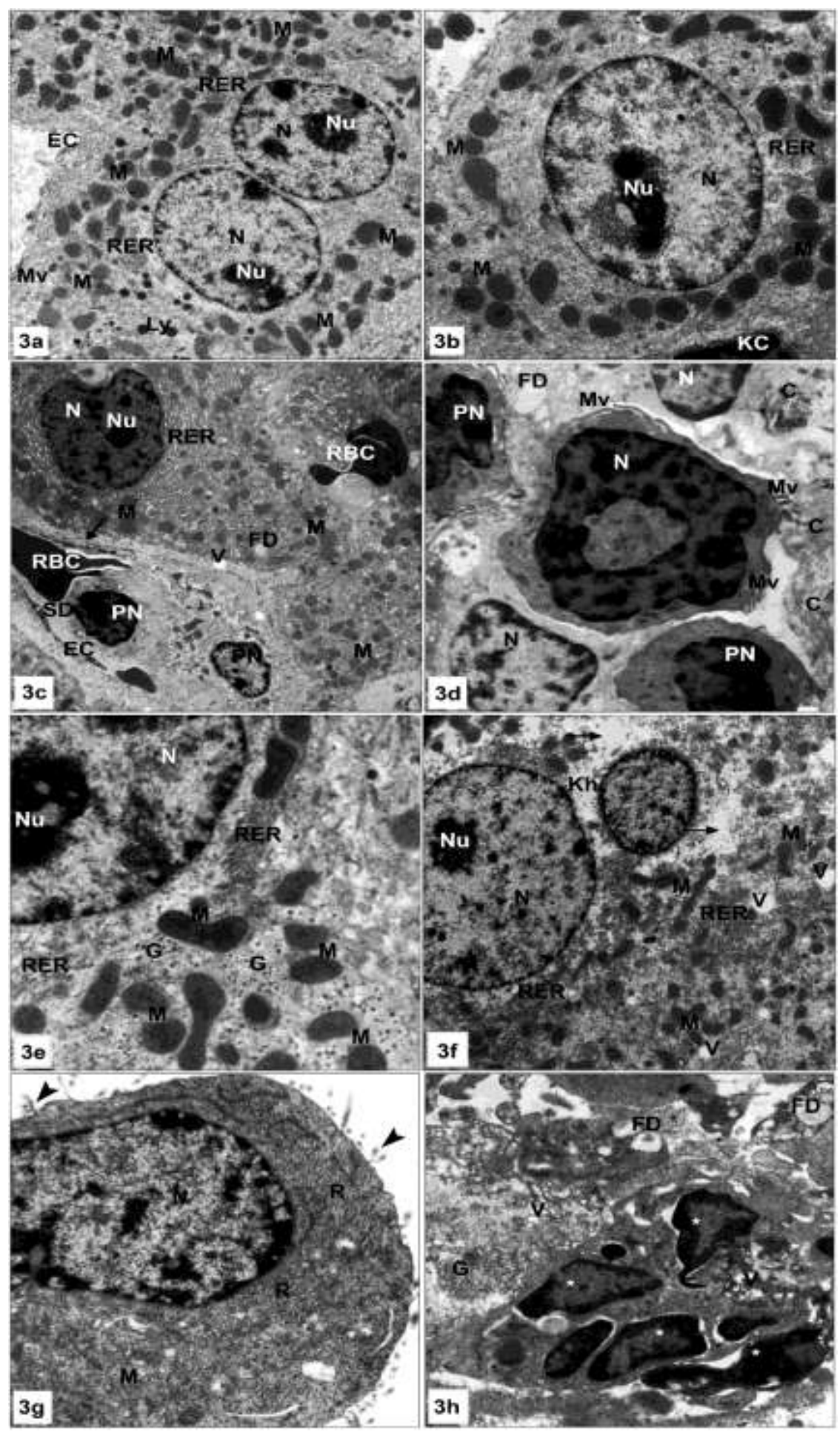

Fig. 3: Electron photomicrograph of liver mice $(a, b)$ control and TQ treated groups respectively illustrating the presence of intact central and spherical nucleus $(\mathrm{N})$, nucleolus $(\mathrm{NU})$, rough endoplasmic reticulum (RER), numerous mitochondria (M), lysosome (Ly), microvilli (Mv), and endothelial cell (EC), and Kupffer cell. (c,d) Ehrlich carcinoma inoculated mice showing irregular shape and large nuclei (N) with nucleoli (NU), mitochondria (M), extensive rough endoplasmic reticulum (RER), space of Disse (SD), endothelial cell (EC), red blood cells (RBCs), pyknotic nuclei (PN), vacuole (V), fat droplets (FD) and Microvilli (arrow), collagen fibers (C) and Microvilli(arrow). (e) TQ pretreated EAC inoculated mice glycogen $(\mathrm{G})$. (f) TQ post-treated EAC inoculated mice karyorrhexis (Kh), dilated rough endoplasmic reticulum (RER) wrapped the altered mitochondria $(\mathrm{M})$, vacuole $(\mathrm{V})$ and necrosis (arrows).(g,h) EAC solid tumor, EAC solid tumor post-treated with TQ, microvilli (arrow), fat droplet (FD), fragmented nuclei $(*)(X, 2000,2500,1500,2500,5000,2000,4000,4000)$ respectively. 


\subsection{Immunohistochemical observations:}

Ki-67, PCNA immunoreactivity was contained in the nucleolus and nucleus. Its appearance was assessed according to the percentage of cells that were definitely stained by the antibody. In control and TQ treated animals liver section had limited number of Ki-67, PCNA positive cells, EAC group displayed enormous nuclear expression. Nevertheless, pre-EAC treated group indicated remarkable reduction in Ki-67 and PCNA labeling index compared to both EAC and/or TQ post-EAC treated groups as shown in Figures 4, 5, 6,7 and table 1 .
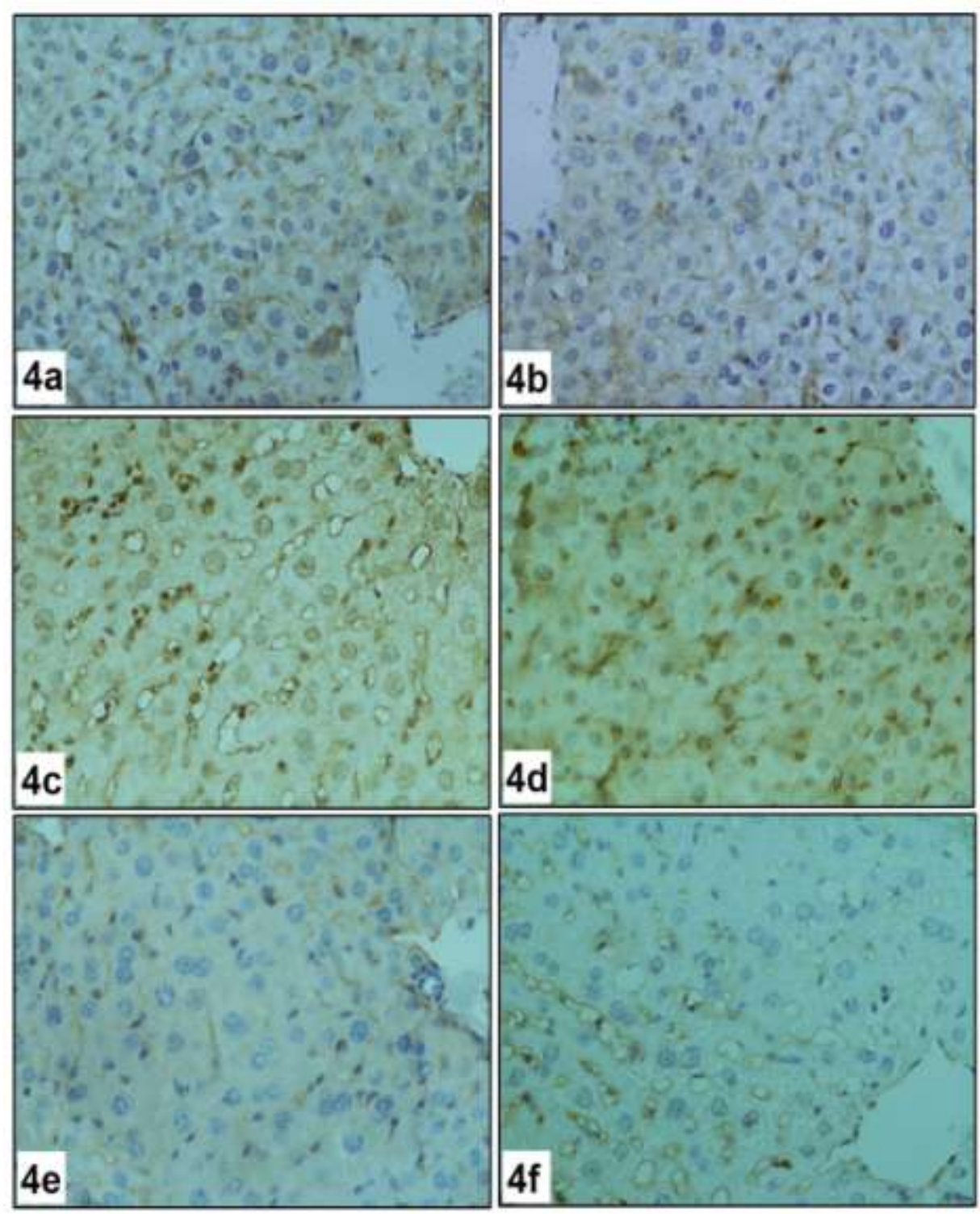

Fig. 4: Photomicrograph of mice of Ki-67 immunostained liver (a,b) control and TQ treated group respectively displaying weak positive stained nuclei. (c,d) EAC inoculated group showing strong range of positive stained nuclei. (e) TQ pre-treated EAC inoculated group illustrated negative stained nuclei. (f) TQ posttreated EAC inoculated animals displaying weak positive reaction. (X 200). 

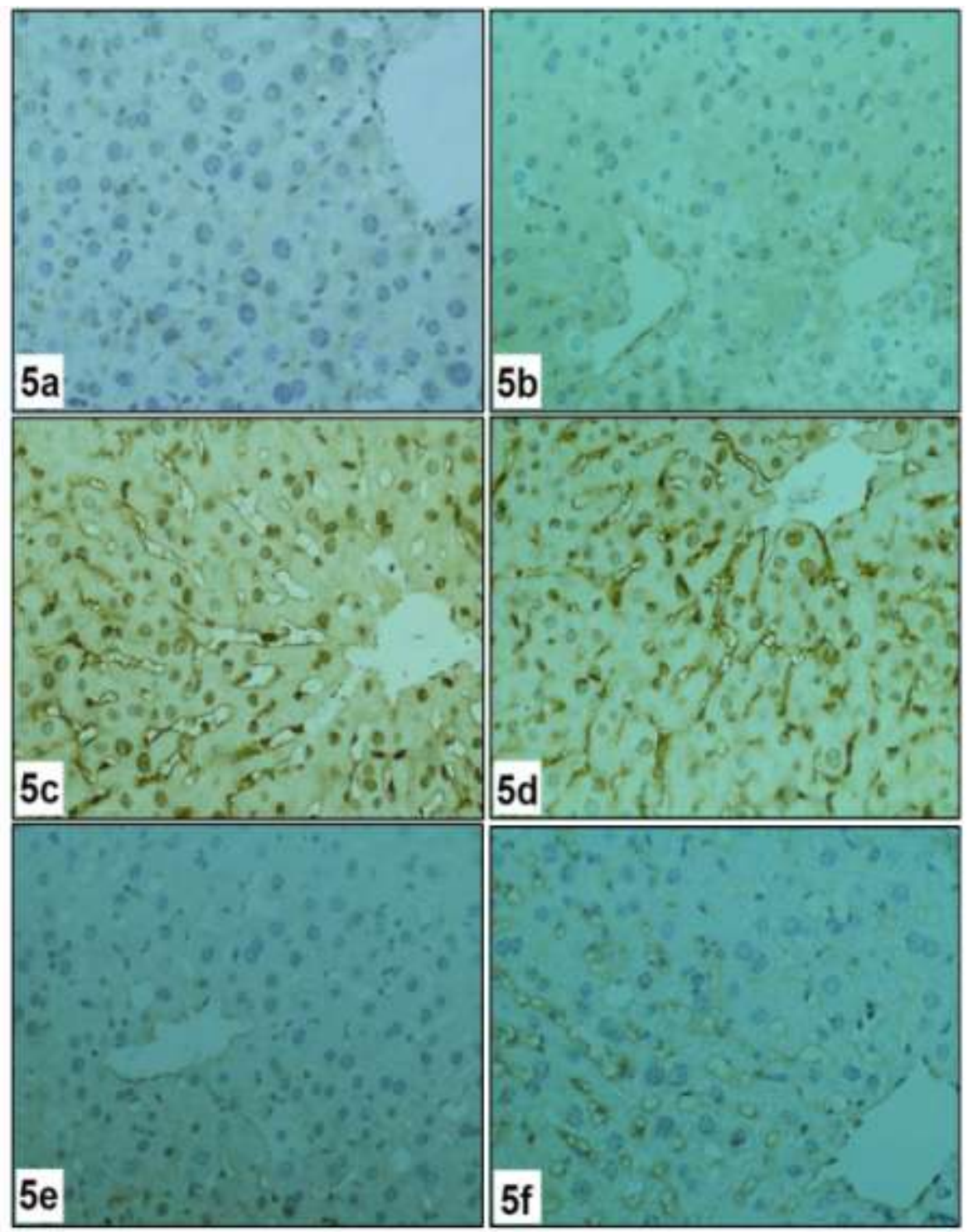

Fig. 5: Photomicrograph of mice of PCNA immunostained liver (a,b) control and TQ treated group respectively displaying weak positive stained nuclei. (c,d) EAC inoculated group showing strong range of positive stained nuclei. (e) TQ pre-treated EAC inoculated group illustrated negative stained nuclei. (f) TQ posttreated EAC inoculated animals displaying weak positive reaction. (X 200).

Table 1: Liver Ki-67 and PCNA labeling index as a result of EAC and/or Thymoquinone treatment:

\begin{tabular}{|l|l|l|l|l|l|}
\hline EAC+TQ & TQ+EAC & EAC & TQ & Control & $\begin{array}{l}\text { Groups } \\
\text { Antigens }\end{array}$ \\
\hline $23.17 \pm 0.54^{\mathrm{a}, \mathrm{b}}$ & $9.17 \pm 0.48^{\mathrm{a}, \mathrm{b}}$ & $72.83 \pm 0.83^{\mathrm{a}}$ & $2 \pm 0.37^{\mathrm{b}}$ & $2.33 \pm 0.33^{\mathrm{b}}$ & Ki-67 \\
\hline $27.33 \pm 0.56^{\mathrm{a}, \mathrm{b}}$ & $9 \pm 0.37^{\mathrm{a}, \mathrm{b}}$ & $78 \pm 0.63^{\mathrm{a}}$ & $2 \pm 0.37^{\mathrm{b}}$ & $3.17 \pm 0.31^{\mathrm{b}}$ & PCNA \\
\hline
\end{tabular}

Data are expressed as mean \pm SE, (a) significant compared to the control $\mathrm{P}<0.05$, (b) significant compared to EAC, $\mathrm{P}<0.05$. 


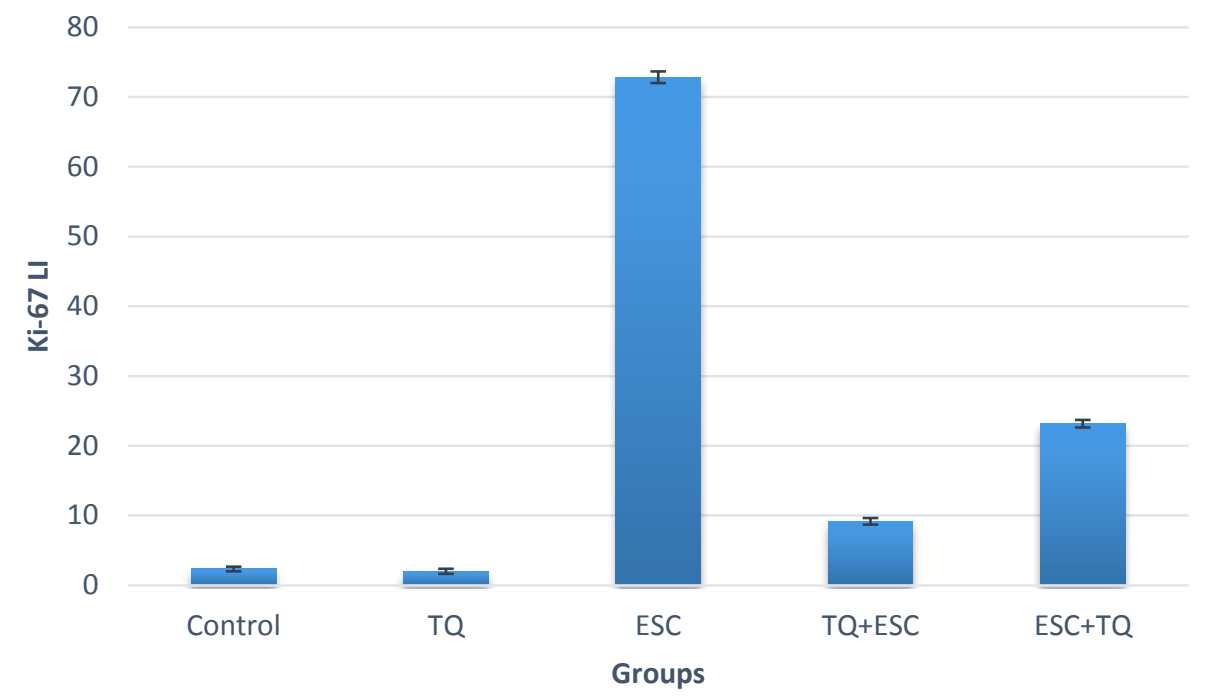

Fig. 6: Hepatocyte Ki-67 labelling index as a result of ESC and /or TQ treatment

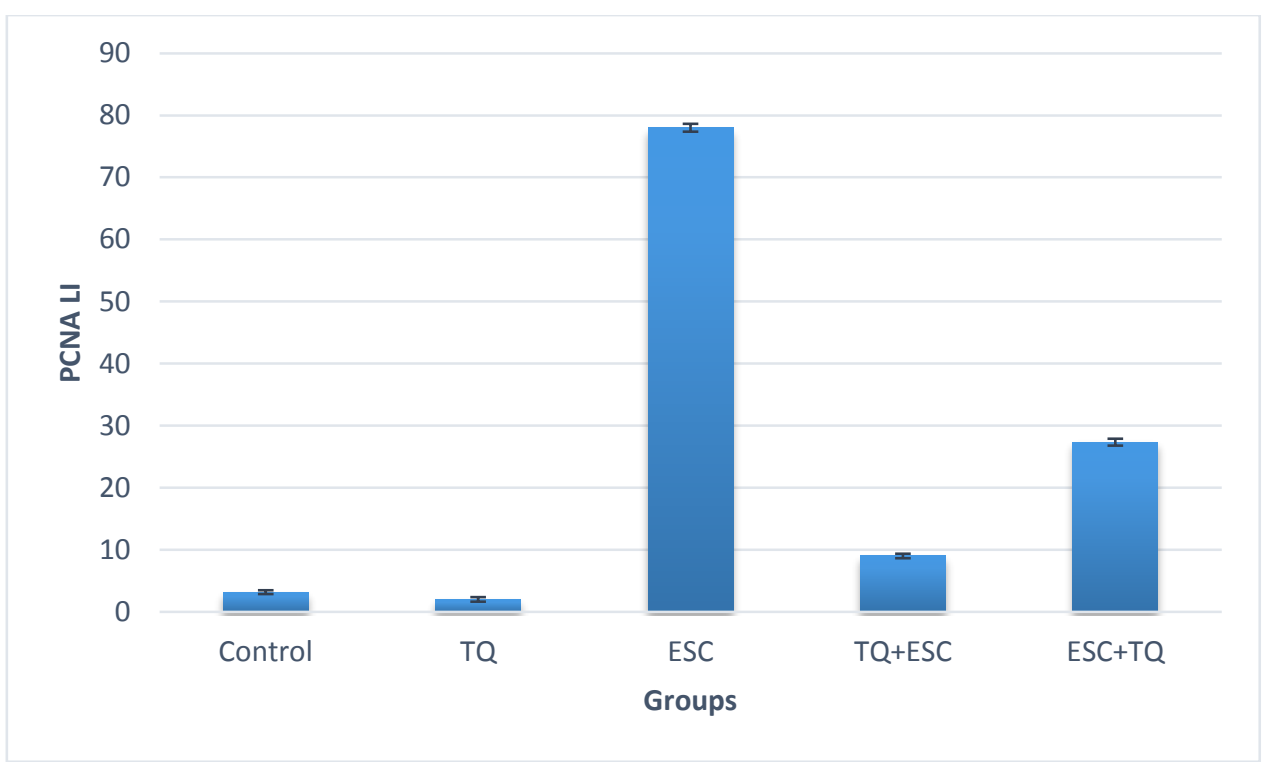

Fig. 7: Hepatocyte PCNA labelling index as a result of ESC and /or TQ treatment

\section{Discussion:}

This article was performed to assess the promising curative and protective influence of TQ on EAC cells inoculated animals. Toxicologically, the liver has a particular interest since hepatocytes exhibiting altered morphological and biochemical properties in response to exposure to hepatocarcinogens(Maronpot and others, 1987). Ehrlich ascites carcinoma (EAC) is considered the popular experimental destructive kind of tumor modeling which easily and rapidly develops after 14 days maximum, achieving great dimensions within few days (Carneiro and others, 2013; Portilho and others, 2011). Chemoprevention offers a tremendous hopeful approach for cancer prevention. Innovative chemo preventive substances of the natural source have been represented by vegetables and fruits to be studied owing to high constituents of bioactive compounds (Rafter, 2002) and their assorted pharmacological properties which are cytotoxic and chemo preventive effects against cancer (Dahiru and others, 2005; Gupta and others, 2004).

Nigella sativa seeds become a useful natural compound(Vihan and Panwar, 2006). Its remedial effects are attributed to Thymoquinone's (The master component of Nigella sativa) that is considered a hopeful natural product within in-vivo and in-vitro studies and numerous-cancer reports (Asaduzzaman Khan and others, 2017; Gali-Muhtasib and others, 2004; Hasan and others, 2013). 
In the present study, EAC inoculated group exhibited a notable diminution in body weight gain compared to normal mice. This finding matches with that of (Badr El-Din and others, 2008; Miranda-Vilela and others, 2011). Body weight fall resulted from the decrease in growth caused by food intake drop and the tumor heaviness with its enormous development degree as well. The drop of tumor volume and body weight gain are the standard measures for assessing the efficiency of any drug against tumors (Miranda-Vilela and others, 2014). Liver tissues of TQ-treated rats showed the normal construction of the liver like that of the control animals demonstrating that TQ treatment did not cause any side effect or hepatotoxicity and this is in agreement with (Attalla F. El-kott and others, 2013; Mohamed and others, 2010). On the other hand, (Sayed-Ahmed and others, 2010) were in disagreement with who mentioned that liver of rats that administered TQ showed a mild degree of hepatic injuries.

EAC subcutaneous inoculated animals displayed increased necrosis, leucocytic infiltration, pleomorphic nuclei and cytoplasmic degeneration that are in agreement with earlier findings (Islam and others, 2013). Moreover, Leucocytic infiltration was believed to be a remarkable reaction of the body organs to stand up for any harmful influences (Sakr, 1999). Certain authors proposed that the cytoplasmic vacuolization is an outcome of marked disruption in the metabolism of fat and lipid. Shrinkage necrosis is an expression of programmed cell death in response to pathological changes (Wyllie and others, 1980). Tumors that comprised necrotic regions, included lysosomes and leucocytes which produces enzymes of elevated lysosomal hydrolase actions (Chen and others, 1996). TQ can maintain the standard performance of liver towards the aggressive action of EAC through the restraining of hepatic enzyme release.

Liver of ESC bearing mice presented lots of alterations caused by lysosomal enzymes and hydration (Morgan and others, 1960; Musa and others, 2004a). ESC cells infiltration probably attributed to tumor proliferation then invade the nearby organs (Chakraborty and others, 2007). Besides, EAC-injected mice revealed huge blocks of tumor pushing and transferred to the muscle tissue, these were in accordance with (Alshaymaa and others, 2012). Liver samples of EAC and TQ-injected group exhibited lack of classic hepatic architecture, these modifications likely as a result of cytoplasmic degeneration (Hashimoto and others, 1995), or perhaps due to mitochondrial degeneration. Necrosis usually includes clusters of nearby cells and causes permanent impairment of cell organelles, (Fukuda and others, 1993).

It is well known that the histological grade of tumor is an evaluation of the level of differentiation of a tumor and pointed to the tumor's aggressiveness (Weigelt and Reis-Filho, 2009). Tumor histopathological and morphometric results indicated that TQ was effective in reducing tumor aggressiveness and in provoking tumor degradation. The presence of pleomorphic microvilli around the nuclei of most hepatocytes was considered to be a cancerous marker (Fukushima and others, 1981). Ultrastructural investigation of EAC inoculated animals revealed destruction and/or absent of microvilli in space of Disse and bile canaliculi. A decrease in microvilli count has been distinguished in hepatitis inoculated mice and after CCl4 administration (Reynolds, 1963; Sherlock and Dooley, 1997).

Fatty acids and other ingredients constituents of TQ are possibly responsible for the anti-tumor action of TQ and the mechanism was proposed by (Ando and others, 1970). Originally, the tumor cell membrane was ruined by fatty acid action (Das, 1989). (Morgan and others, 1960) stated that fatty acid length suppressed tumor progression in vitro. Comparable research was done on Nigella sativa seeds (Salomi and others, 1992). Our investigations reinforced that TQ possesses scavenging influence against oxidative stress induced through EAC. Modern studies discusses that ethanolic extract of Nigella sativa seeds has antitumor property(Musa and others, 2004b). On the other hand, the present data revealed that TQ extract administration improved liver injuries induced by EAC cells that is represented in light and electron microscopy micrographs and these results goes parallel to that obtained by (Fatma and others, 2011; Jafri and others, 2010; Li and others, 2010).

Some of the hepatic cells displayed reduction instead of swelling which is a distinct characteristic of apoptosis. Apoptosis is the programmed cell death that prompted by specific enzymes which destroyed DNA (Kumar and others, 2009). This typical phenomenon serves to eliminate undesirable cells during development (Fadeel and Orrenius, 2005). Beginning of apoptosis happens through signals from two separate pathways: the intrinsic or (the mitochondrial) pathway and the extrinsic or (death receptor-initiated) pathway. Both of them stimulate caspases, that are cell death mediators (Danial and Korsmeyer, 2004).

These results were supported by cytological examination that revealed a noteworthy rise in number of mitotic cells of positive control group. Conversely, the cytological examination of EAC cells in both preventive and protective mice, revealed a significant decrease in number of mitotic cells compared to positive normal one. Moreover, there was insignificant variance between preventive and protective mice in the appearance and morphology of ESC cells. This was in agreement with (Simoni and others, 2001)Arindam et al. (2003) who identified apoptotic features as well. Also (Pauloin and others, 2008) reviewed that during early apoptosis, cells presenting severe compressed chromatin, splitting nuclei, and conserved cytoplasmic organelles, conversely, in late apoptosis cells presented alike features, but lacking nuclear cover and most organelles. In addition to significant increase in necrotic spots, TQ treatment stimulated necrosis in the marginal regions of tumors. These regions are of penetrative neoplastic feature (Gali-Muhtasib and others, 2005; Kaseb and others, 2007; Roepke 
and others, 2007). TQ is probably slightly toxic to intact cells. Moreover, these results suggested that TQ stops tumor progression and could be considered as a cancer therapy prospective remedy candidate (Assaf and others, 2017; Mostofa and others, 2017). TQ pre-treated mice displayed a negligible pathological features to a great degree compared to that of control mice's liver.

Feulgen reaction proposed 75 years ago is a kind of histochemical reactions commonly applied in biology. It is a good indicator of DNA state providing significant information about biological behavior of cells. DNA staining strength is relational to the DNA intensity which is a good indicator of liver cell apoptosis (Chieco and Derenzini, 1999). DNA content of control cells using Feulgen reaction appeared magenta red in color and sections examined after Ehrlich carcinoma cells inoculation showed a marked decrease in the DNA content. These findings were consistent with (Musa and others, 2004b). Many factors have been suggested to interfere with the reduction of DNA; one of the main factors is lysosomal particles and their contents of hydrolytic enzymes. Once the lysosomal membranes are disrupted under any pathological conditions, these enzymes become free in the cytoplasm causes obvious degradation of DNA and proteins. This concept confirms the findings of (Awasthi and others, 1984). Furthermore, (Musa and others, 2004b) investigated the effective action of Nigella sativa seeds in inhibiting the tumor cells propagation and reducing the mitotic index in the treated mice. These results confirmed that were achieved by (Salomi and others, 1992). Besides, liver samples revealed rearrangement of most diploid cells, lack of aneuploid cells with rise in proliferation index and an elevation in DNA content as well as. These outcomes probably owing to TQ and its ingredients' antioxidant features. This study revealed that TQ could prevent the development of tumor and shows deletion in tumor progress.

Regarding to Ki-67, (Ito and others, 1999) stated thatKi-67 expression levels are important in assessing carcinogenicity of chemicals in rat, and its existence through different phases of the cell cycle considering it as a perfect indicator for neoplasia. Our investigations were matched with the results of (Pizem and others, 2001) who mentioned that Ki-67 and PCNA and were valuable for proliferation assessment of hepatic cells. They showed a statistically considerable connection between Ki-67 and PCNA proliferative indexes in HCC in addition to affirmative connection between Ki-67 index and tumor stage. Besides, the investigation of (Stroescu and others, 2008) exhibited that immunostaining of HCC for Ki-67 was correlated with increased mitotic action.

\section{Conclusion:}

The outcomes of the current investigation are encouraging, and Thymoquinone has revealed a remarkable drop in cell propagation, DNA production, and elongation of lifespan of the animals with the Ehrlich ascites tumor. Overall, extra evaluation of Thymoquinone is strongly recommended within clinical and scientific fields to outline its possible value to be utilized as an innovative complementary remedy for cancer diseases.

\section{ACKNOWLEDGMENT}

The authors greatly indebted to Department of Zoology, Faculty of science at Mansoura University for providing us with almost all needful supplies.

\section{Conflict of interest:}

All authors declare no conflict of interests.

\section{REFERENCES}

Al-Ali, A., A.A. Alkhawajah, M.A. Randhawa, N.A. Shaikh, 2008. Oral and intraperitoneal LD50 of thymoquinone, an active principle of Nigella sativa, in mice and rats. Journal of Ayub Medical College, Abbottabad : JAMC 20(2): 25-27.

Alshaymaa, A., El-Bahy, Khaled Abou-Aisha, Eman Noaman, L.G. Mahran, 2012. Regression of Murine Ehrlich Ascites Carcinoma Using Tumor-Targeting Salmonella VNP20009 - Comparison with the Effect of the Anticancer Drug Doxorubicin. Advances in Cancer: Research \& Treatment:20.

Ando, K., S. Suzuki and M. Arita, 1970. Synthesis of mycophenolic acid beta-D-glucuronide and its antitumor activity. J Antibiot (Tokyo) 23(8): 408-413.

Apryshko, G.N., V.N. Ivanov, N.A. Milchakova, M.V. Nekhoroshev, 2005. Mediterranean and Black Sea organisms and algae from mariculture as sources of antitumor drugs. Experimental oncology, 27(2): 94-95.

Asaduzzaman Khan, M., M. Tania, S. Fu, J. Fu, 2017. Thymoquinone, as an anticancer molecule: from basic research to clinical investigation. Oncotarget, 8(31): 51907-51919.

Assaf, M.D., J. Semaan, M. El-Sabban, S.K. Al-Jaouni, R. Azar, M.A. Kamal, S. Harakeh, 2017. Inhibition of proliferation and induction of Apoptosis by Thymoquinone via modulation of TGF family, p53, p21 and Bcl2alpha in leukemic cells. Anti-cancer agents in medicinal chemistry. 
Attalla F. El-kott, Ahmad A. Kandeel, Sayed F. Abed El-Aziz, H.M. Ribea, 2013. The Histopathological, Immunohistochemical And Ultrastructural Alterations Following Administration Of Nigella Sativa In Rats Hepatocellular Carcinoma. Cancer Therapy, 9: 30-39.

Awasthi, M., P. Shah, M.S. Dubale, P. Gadhia, 1984. Metabolic changes induced by organophosphates in the piscine organs. Environmental research, 35(1): 320-325.

Badary, O.A., M.F. Abd-Ellah, M.A. El-Mahdy, S.A. Salama, F.M. Hamada, 2007. Anticlastogenic activity of thymoquinone against benzo(a)pyrene in mice. Food and chemical toxicology : an international journal published for the British Industrial Biological Research Association, 45(1): 88-92.

Badary, O.A., O.A. Al-Shabanah, N.M. Al-Gharably, M.M. Elmazar, 1998. Effect of Cremophor EL on the pharmacokinetics, antitumor activity and toxicity of doxorubicin in mice. Anti-cancer drugs, 9(9): 809-815.

Badr El-Din, N.K., E. Noaman, M. Ghoneum, 2008. In vivo tumor inhibitory effects of nutritional rice bran supplement MGN-3/Biobran on Ehrlich carcinoma-bearing mice. Nutrition and cancer, 60(2): 235-244.

Carneiro, M.L., R.C. Peixoto, G.A. Joanitti, R.G. Oliveira, L.A. Telles, A.L. Miranda-Vilela, A.L. Bocca, L.M. Vianna, I.C. da Silva, A.R. de Souza and others, 2013. Antitumor effect and toxicity of free rhodium (II) citrate and rhodium (II) citrate-loaded maghemite nanoparticles in mice bearing breast cancer. Journal of nanobiotechnology, 11: 4.

Chakraborty, T., D. Bhuniya, M. Chatterjee, M. Rahaman, D. Singha, B.N. Chatterjee, S. Datta, A. Rana, K. Samanta, S. Srivastawa and others, 2007. Acanthus ilicifolius plant extract prevents DNA alterations in a transplantable Ehrlich ascites carcinoma-bearing murine model. World journal of gastroenterology, 13(48): 6538-6548.

Chen, L., P.D. Devanesan, S. Higginbotham, F. Ariese, R. Jankowiak, G.J. Small, E.G. Rogan, E.L. Cavalieri, 1996. Expanded analysis of benzo[a]pyrene-DNA adducts formed in vitro and in mouse skin: their significance in tumor initiation. Chemical research in toxicology, 9(5): 897-903.

Chieco, P., M. Derenzini, 1999. The Feulgen reaction 75 years on. Histochemistry and cell biology, 111(5): 345-358.

Dahiru, D., E.T. William, M.S. Nadro, 2005. Protective effect of Zizyphus mauritiana leaf extract on carbon tetrachloride-induced liver injury. Afr J Biotechnol., 4(10): 1177-1179.

Danial, N.N., S.J. Korsmeyer, 2004. Cell death: critical control points. Cell 116(2):205-219.

Das AK. 1989. Antitumor property of the active principle of jawaharene. Cancer letters, 48(2): 147-151.

Fadeel, B., S. Orrenius, 2005. Apoptosis: a basic biological phenomenon with wide-ranging implications in human disease. Journal of internal medicine, 258(6): 479-517.

Fatma, M.L., A.A. Mona, A.A. Abeer and K.S. Mona, 2011. Protective Effect of Thymoquinone against DGalactosamine-Induced Liver Injury in Rats. Australian Journal of Basic and Applied Sciences, 5(2): 49-58.

Fukuda, K., M. Kojiro, J.F. Chiu, 1993. Demonstration of extensive chromatin cleavage in transplanted Morris hepatoma 7777 tissue: apoptosis or necrosis? The American journal of pathology, 142(3): 935-946.

Fukushima, S., S.M. Cohen, M. Arai, J.B. Jacobs, G.H. Friedell, 1981. Scanning electron microscopic examination of reversible hyperplasia of the rat urinary bladder. The American journal of pathology, 102(3): 373-380.

Gali-Muhtasib, H., M. Diab-Assaf, C. Boltze, J. Al-Hmaira, R. Hartig, A. Roessner, R. Schneider-Stock, 2004. Thymoquinone extracted from black seed triggers apoptotic cell death in human colorectal cancer cells via a p53-dependent mechanism. International journal of oncology, 25(4): 857-866.

Gali-Muhtasib, H., A. Roessner, R. Schneider-Stock, 2006. Thymoquinone: a promising anti-cancer drug from natural sources. The international journal of biochemistry \& cell biology, 38(8): 1249-1253.

Gali-Muhtasib, H.U., M. Diab-Assaf, M.J. Haddadin, 2005. Quinoxaline 1,4-dioxides induce G2/M cell cycle arrest and apoptosis in human colon cancer cells. Cancer chemotherapy and pharmacology, 55(4): 369378.

Garvin, A.J., B.J. Hall, R.M. Brissie, S.S. Spicer, 1976. Cytochemical differentiation of nucleic acids with a Schiff-methylene blue sequence. The journal of histochemistry and cytochemistry : official journal of the Histochemistry Society, 24(4): 587-590.

Global Burden of Disease Cancer C., C. Fitzmaurice, D. Dicker, A. Pain, H. Hamavid, M. Moradi-Lakeh, M.F. MacIntyre, C. Allen, G. Hansen, R. Woodbrook and others, 2015. The Global Burden of Cancer 2013. JAMA oncology, 1(4): 505-527.

Gupta, M., U.K. Mazumder, M.L. Vamsi, T. Sivakumar, C.C. Kandar, 2004. Anti-steroidogenic activity of the two Indian medicinal plants in mice. Journal of ethnopharmacology, 90(1): 21-25.

Hasan, T.N., G. Shafi, N.A. Syed, M.A. Alfawaz, M.A. Alsaif, A. Munshi, K.Y. Lei, A.A. Alshatwi, 2013. Methanolic extract of Nigella sativa seed inhibits SiHa human cervical cancer cell proliferation through apoptosis. Natural product communications, 8(2): 213-216.

Hashimoto, S., T. Koji, J. Niu, T. Kanematsu, P.K. Nakane, 1995. Differential staining of DNA strand breaks in dying cells by non-radioactive in situ nick translation. Archives of histology and cytology, 58(2): 161170. 
Horiguchi, N., E.J. Ishac, B. Gao, 2007. Liver regeneration is suppressed in alcoholic cirrhosis: correlation with decreased STAT3 activation. Alcohol., 41(4): 271-280.

Islam, F., S.M. Ali, J.A. Khanam, 2013. Hepatoprotective effect of acetone semicarbazone on Ehrlich ascites carcinoma induced carcinogenesis in experimental mice. Asian Pacific journal of tropical biomedicine, 3(2): 105-110.

Ito, Y., N. Matsuura, M. Sakon, T. Takeda, K. Umeshita, H. Nagano, S. Nakamori, K. Dono, M. Tsujimoto, M. Nakahara and others, 1999. Both cell proliferation and apoptosis significantly predict shortened disease-free survival in hepatocellular carcinoma. British journal of cancer, 81(4): 747-751.

Jafri, S.H., J. Glass, R. Shi, S. Zhang, M. Prince, H. Kleiner-Hancock, 2010. Thymoquinone and cisplatin as a therapeutic combination in lung cancer: In vitro and in vivo. Journal of experimental \& clinical cancer research : CR 29: 87.

Kasas, S., G. Dumas, G. Dietler, S. Catsicas, M. Adrian, 2003. Vitrification of cryoelectron microscopy specimens revealed by high-speed photographic imaging. Journal of microscopy, 211(Pt 1): 48-53.

Kaseb, A.O., K. Chinnakannu, D. Chen, A. Sivanandam, S. Tejwani, M. Menon, Q.P. Dou, G.P. Reddy, 2007. Androgen receptor and E2F-1 targeted thymoquinone therapy for hormone-refractory prostate cancer. Cancer research, 67(16): 7782-7788.

Kumar, V., A. Abbas, N. Fausto and J. Aster, 2009. Cellular responses to stress and toxic insults: Adaptation, injury and death. In Robbins and Cortan Pathologic Basis of Disease (8th ed).

Li, F., P. Rajendran, G. Sethi, 2010. Thymoquinone inhibits proliferation, induces apoptosis and chemosensitizes human multiple myeloma cells through suppression of signal transducer and activator of transcription 3 activation pathway. British journal of pharmacology, 161(3): 541-554.

Maronpot, R.R., J.K. Haseman, G.A. Boorman, S.E. Eustis, G.N. Rao, J.E. Huff, 1987. Liver lesions in B6C3F1 mice: the National Toxicology Program, experience and position. Archives of toxicology Supplement = Archiv fur Toxikologie Supplement, 10: 10-26.

Miranda-Vilela, A.L., C.K. Grisolia, J.P. Longo, R.C. Peixoto, M.C. de Almeida, L.C. Barbosa, M.M. Roll, F.A. Portilho, L.L. Estevanato, A.L. Bocca and others, 2014. Oil rich in carotenoids instead of vitamins C and E as a better option to reduce doxorubicin-induced damage to normal cells of Ehrlich tumor-bearing mice: hematological, toxicological and histopathological evaluations. The Journal of nutritional biochemistry 25(11):1161-1176.

Miranda-Vilela, A.L., F.A. Portilho, V.G. de Araujo, L.L. Estevanato, B.P. Mezzomo, F. Santos Mde, Z.G. Lacava, 2011. The protective effects of nutritional antioxidant therapy on Ehrlich solid tumor-bearing mice depend on the type of antioxidant therapy chosen: histology, genotoxicity and hematology evaluations. The Journal of nutritional biochemistry, 22(11): 1091-1098.

Mohamed, H.A., I.H. El-Sayed, M. Moawad, 2010. Protective effect of Nigella sativia seeds against dimethylaminoazobenzene (DAB) induced liver carcinogenesis. Nature and Science., 8(6): 80-87.

Morgan, J.F., S. Tolnai, G.F. Townsend, 1960. Studies on the in vitro antitumor activity of fatty acids. II. Saturated dicarboxylic acids. Canadian journal of biochemistry and physiology, 38: 597-603.

Mostofa, A.G.M., M.K. Hossain, D. Basak, M.S. Bin Sayeed, 2017. Thymoquinone as a Potential Adjuvant Therapy for Cancer Treatment: Evidence from Preclinical Studies. Frontiers in pharmacology 8:295.

Musa D, Dilsiz N, Gumushan H, Ulakoglu G, Bitiren M. 2004a. Antitumor activity of an ethanol extractof Nigella sativa seeds. Biologia, Bratislava, 59(6): 735-740.

Musa, D., N. Dilsiz, G. Ulakoglu, G. Ulakoglu, M. Bitiren, 2004b. Antitumor activity of an ethanol extract of Nigella sativa seeds. Biologia, 59: 735-740.

Nagi, M.N., K. Alam, O.A. Badary, O.A. al-Shabanah, H.A. al-Sawaf, A.M. al-Bekairi, 1999. Thymoquinone protects against carbon tetrachloride hepatotoxicity in mice via an antioxidant mechanism. Biochemistry and molecular biology international., 47(1): 153-159.

Ozaslan, M., I.D. Karagoz, I.H. Kilic, M.E. Guldur, 2011. Ehrlich ascites carcinoma. Afr J Biotechnol., 10(13): 2375-2378.

Pauloin, T., M. Dutot, J.M. Warnet, P. Rat, 2008. In vitro modulation of preservative toxicity: high molecular weight hyaluronan decreases apoptosis and oxidative stress induced by benzalkonium chloride. European journal of pharmaceutical sciences : official journal of the European Federation for Pharmaceutical Sciences, 34(4-5): 263-273.

Pizem, J., V.F. Marolt, B. Luzar, A. Cor, 2001. Proliferative and apoptotic activity in hepatocellular carcinoma and surrounding non-neoplastic liver tissue. Pflugers Archiv : European journal of physiology, 442(6 Suppl 1): R174-176.

Portilho, F.A., L.L.C. Estevanato, A.L. Miranda-Vilela, M.F.M. Almeida-Santos, C.E. de OliveiraCavalcanti, B.M. Lacava, et al., 2011. Investigation of a magnetohyperthermia system efficacy. Journal of applied physiology 109(07B307).

Rafter, J.J., 2002. Scientific basis of biomarkers and benefits of functional foods for reduction of disease risk: cancer. The British journal of nutrition 88 Suppl., 2: S219-224. 
Reynolds, E.S., 1963. Liver Parenchymal Cell Injury. I. Initial Alterations of the Cell Following Poisoning with Carbon Tetrachloride. The Journal of cell biology, 19: 139-157.

Roepke, M., A. Diestel, K. Bajbouj, D. Walluscheck, P. Schonfeld, A. Roessner, R. Schneider-Stock, H. Gali-Muhtasib, 2007. Lack of p53 augments thymoquinone-induced apoptosis and caspase activation in human osteosarcoma cells. Cancer biology \& therapy, 6(2): 160-169.

Salomi, N.J., S.C. Nair, K.K. Jayawardhanan, C.D. Varghese, K.R. Panikkar, 1992. Antitumour principles from Nigella sativa seeds. Cancer letters, 63(1): 41-46.

Sayed-Ahmed, M.M., A.M. Aleisa, S.S. Al-Rejaie, A.A. Al-Yahya, O.A. Al-Shabanah, M.M. Hafez, M.N. Nagi, 2010. Thymoquinone attenuates diethylnitrosamine induction of hepatic carcinogenesis through antioxidant signaling. Oxidative medicine and cellular longevity, 3(4): 254-261.

Sherlock, S., J. Dooley, 1997. Diseases of the Liver and Biliary System. 9th edition. Germany: WileyBlackwell.

Simoni, D., M. Roberti, F.P. Invidiata, R. Rondanin, R. Baruchello, C. Malagutti, A. Mazzali, M. Rossi, S. Grimaudo, F. Capone and others, 2001. Heterocycle-containing retinoids. Discovery of a novel isoxazole arotinoid possessing potent apoptotic activity in multidrug and drug-induced apoptosis-resistant cells. Journal of medicinal chemistry, 44(14): 2308-2318.

Stojkovic, R., M. Radacic, 2002. Cell killing of melanoma B16 in vivo by hyperthermia and cytotoxins. International journal of hyperthermia: the official journal of European Society for Hyperthermic Oncology, North American Hyperthermia Group, 18(1): 62-71.

Stroescu, C., A. Dragnea, B. Ivanov, C. Pechianu, V. Herlea, O. Sgarbura, A. Popescu, I. Popescu, 2008. Expression of p53, Bcl-2, VEGF, Ki67 and PCNA and prognostic significance in hepatocellular carcinoma. Journal of gastrointestinal and liver diseases : JGLD 17(4): 411-417.

Vihan, V.S., H.S. Panwar, 2006. Galactopoitic effect of Nigella sativa in clinical cases of galactia goats. Indian Vet J 64: 247-249.

Weigelt, B., J.S. Reis-Filho, 2009. Histological and molecular types of breast cancer: is there a unifying taxonomy? Nature reviews Clinical oncology, 6(12): 718-730.

Wyllie, A.H., J.F. Kerr, A.R. Currie, 1980. Cell death: the significance of apoptosis. International review of cytology, 68: 251-306.

Xie, J.T., C.Z. Wang, S. Wicks, J.J. Yin, J. Kong, J. Li, Y.C. Li, C.S. Yuan, 2006. Ganoderma lucidum extract inhibits proliferation of SW 480 human colorectal cancer cells. Experimental oncology, 28(1): 25-29. 